\title{
A Study on Writing Anxiety among Iranian EFL Students
}

\author{
Naghmeh Jebreil \\ Department of English Language Teaching, Islamic Azad University, Ilam Branch, Ilam, Iran \\ Akbar Azizifar (Corresponding Author) \\ Department of English Language Teaching, Islamic Azad University, Ilam Branch, Ilam, Iran \\ Habib Gowhary \\ Department of English Language Teaching, Islamic Azad University, Ilam Branch,Ilam, Iran \\ Ali Jamalinesari \\ Department of English Language and Literature, Islamic Azad University, Ilam Branch, Ilam, Iran
}

Received: 28-07-2014

doi:10.7575/aiac.ijalel.v.4n.2p.68
Accepted: 23-09-2014

Published: 01-03-2015

\begin{abstract}
This article aimed at investigating the level of writing anxiety of the Iranian EFL students with different proficiency levels. To do so, 45 students (elementary, intermediate, and advanced learners) studying in Azad University of Ilam, Iran were selected based on random sampling. Second, Language Writing Anxiety Inventory SLWAI (Cheng, 2004) was used to measure anxiety. Both descriptive and inferential statistics including One-way ANOVA were run to analyze the data. Statistical analysis was conducted using Statistical Package for Social Science (SPSS). The results of the study indicated that the selected Iranian EFL students majoring in English language teaching experienced a high level of anxiety. In addition, students with elementary level were found to suffer higher level of English writing anxiety than the students with intermediate and advanced levels. Finally, based on the findings, cognitive anxiety was the most common type of anxiety, followed by somatic anxiety, and avoidance behavior. The results also highlighted the fact that foreign and second language teachers should be cautious of the dangers of anxiety and try to make the atmosphere of class as stress-free as possible in order to improve students' performance.
\end{abstract}

Keywords: Writing Anxiety, EFL Students, Cognitive Anxiety, Somatic Anxiety, Avoidance

\section{Introduction}

Second language researchers and theorists have long been aware that anxiety is often associated with second language learning. Teachers and learners generally feel that anxiety is a major obstacle to be overcome in second language learning (Horwitz, Horwitz \& Cope, 1986). In advanced American English Longman (2005), anxiety is defined as a feeling of being very worried about something that may happen or may have happened, so that you think about it all the time or is a feeling of wanting to do something very much, but being very worried that you will not succeed. It is associated with feelings of uneasiness, frustration, self-doubt, apprehension or worry (Scovels, 1978). According to different studies, anxiety has a relation with foreign language anxiety. Anxiety can have both positive and negative effects on performance (Alpert \& Haber, 1960; Lehrer, Goldman, \& Strommen, 1990). Second language writing anxiety (SLWA) can be defined as "a general avoidance of writing and of situations perceived by the individuals to potentially require some amount of writing accompanied by the potential for evaluation on that writing" (Hassan, 2001, P.4). Studies on ESL (English as a second language) writing showed that ESL writing anxiety can have profound effects on ESL writing performance (Hassan, 2001, P.18-21; Horwitz, 2001, P.115-117; Cheng, 2004, P.329-331). Some studies showed that students with high levels of writing anxiety wrote shorter composition and qualified their writing less than their low anxious counterparts did (Hassan, 2001, P.20-21). Cheng analyzed factors associated with second language writing anxiety (Cheng, 2002), and he also offered a measure, the Second Language Writing Anxiety Inventory (SLWAI), to assess the levels and types of second language writing anxiety (Cheng, 2004). Though SLWA has been increasingly recognized by more and more researchers and educators, few studies can be found that have investigated the simultaneous interaction anxiety and different language proficiency levels. The present study tries to investigate the anxiety among Iranian EFL students with different language proficiency levels (elementary, intermediate, and advanced).

\section{Review of Literature}

\subsection{Definition and Types of Anxiety}

Anxiety as "a subjective feeling of tension, apprehension, nervousness, and worry associated with an arousal of the automatic nervous system" (Horwitz et al, 1986, p. 125). 
In psychology, anxiety is broadly defined as, "the awareness of threat" (Tyrer, 1999, p. 11). Cope and Horwitz (1986) provided an explanation which described anxiety concerning foreign language anxiety as "a distinct complex of selfperceptions, beliefs, feelings, and behaviors related to classroom language learning arising from the uniqueness of the language learning process" (P.128).

Psychologists make a distinction between three categories of anxiety: trait anxiety, state anxiety, and situation-specific anxiety. Trait anxiety is relatively stable personality characteristic, 'a more permanent predisposition to be anxious' (Scovel, 1978). While state anxiety is a transient anxiety, responses to a particular anxiety provoking stimulus such as an important test (Spielberger, (1983): cited in Horwitz, (2001)). The third category, situation-specific anxiety, refers to the persistent and multi-faceted nature of some anxieties (MacIntyre \& Gardner, (1991): cited in Horwitz, (2001)). In the case of language learning, situation specific anxiety refers to apprehension caused by learners' inadequate knowledge of language (Macintyre \& Gardner, 1991). Most researchers accept the idea that foreign language anxiety is a situation-specific anxiety related to the language learning context and that it can play a significant casual role in creating individual differences in language learning. Horwitz (2001) notes that several studies have found foreign language anxiety to be largely independent of other types of anxiety. Since this approach has been taken, the results of studies on foreign language anxiety and achievement have been relatively uniform. Brown (2000) believes that anxiety could be distinguished into debilitative and facilitative anxiety. The negative kind of anxiety is sometimes called "debilitative anxiety", because it damages learners' performance in many ways. There is usually little cause for debilitating anxiety (Ehrman, 1996). In the literature, debilitative anxiety has been strongly supported by many researchers because their studies all showed the negative correlation of anxiety with grades in language courses (Aida, 1994). Contrary to the concept of "debilitative anxiety", some researchers have suggested that language anxiety is helpful in some ways for some learners. This positive aspect of anxiety is called "facilitative anxiety. Ehrman (1996) called the situation in those words "tension or arousal". Even though some people hate learning under tension, they still believe that sometimes tension is good for learning (Spielmann, 2001).

\subsection{Definition and Types of SLWA}

Writing anxiety, as a subject and situation specific anxiety was defined as "a general avoidance of writing behavior and of situations thought to potentially require some amount of writing accompanied by the potential for evaluation of that writing" (Hassan, 2001, P.4). Cheng (2004) offered a multidimensional L2 writing scale - the Second Language Writing Anxiety Inventory (SLWAI) which conforms to a three-dimensional conceptualization of anxiety, such as Somatic Anxiety, Cognitive Anxiety, and Avoidance Behavior. Somatic Anxiety refers to one's perception of the physiological effects of the anxiety experience, as reflected in increase in state of unpleasant feelings, such as nervousness and tension (Cheng, 2004). Cognitive Anxiety refers to the cognitive aspect of anxiety experience, including negative expectations, preoccupation with performance and concern about others' perception (Cheng, 2004). Avoidance Behavior refers to the behavioral aspect of the anxiety experience, avoidance of writing (Cheng, 2004). Cheng (2004) also pointed out that the negative relationship between test anxiety and L2 writing performance is primarily due to the negative components rather than somatic components or avoidance behavior. Studies by Chen and Lin (2009) and Saito and Samimy (1996) indicate that writing anxiety is negatively related to performance on writing tasks. "score lower on writing portions of standardized tests, write less, write less effectively, and create written products that are evaluated as lower in quality than less anxious writers" (Daly \& Wilson, 1983, p. 328).

\section{Methodology}

\subsection{Sample}

A total number of 45 male and female students constituted the subjects of this study. The participants were English language students majoring in English language teaching from Azad University in Ilam, science and research branch.

\subsection{Instrumentation}

In the present study, two instruments were used, with the purpose of collecting the data. The first one was the Michigan Test of English Language Proficiency (MTELP). Its validity and reliability was assumed to be satisfactory. The next questionnaire was Second Language Writing Anxiety Inventory (SLWAI). It consists of 22 items, based on the SLWAI (Cheng, 2004), which was designed to assess if there is ESL writing anxiety among Iranian EFL learners and to what level. The SLWAI scored on a five-point likert response scale ranging from 1(strongly disagree) to 5(strongly agree). Five of the items $(1,4,17,18$, and 22) are negatively worded and require reversely scored before being summed up to yield total scores. A higher score obtained thereupon indicates a higher level of ESL writing anxiety. A total score above 65 points indicates a high level of writing anxiety, a total score below 50 points indicates a low level of writing anxiety, and a total score in-between indicates a moderate level of writing anxiety.

\subsection{Data Collection and Analysis Procedure}

After the introductory studies and needs analysis, above mentioned instrument was selected to glean the data. Then, a pilot study was run to revise the questionnaire. After that, the necessary revision and modifications were done and some factors were added to make the items more clear and detailed. Then, after permission was given by the university in April, 2014, the questionnaire was administrated in Ilam. The time allocated for completing questionnaire was roughly 15 minutes. In order to increase the credibility of the responses, the researcher asked the students to be sincere in their responses and provide genuine answer to the items on the questionnaire. Finally the participants were assured that the results of the questionnaire will be kept confidential. Data from returned survey were entered into and analyzed using Statistical Package for Social Science (SPSS) to get descriptive analysis and one-way ANOVA. 


\section{Results}

\subsection{Investigating the research question of the study}

The main objective of this study is to find out if there is ESL writing anxiety among Iranian EFL students with different proficiency levels and to what level. For this purpose, the related data were collected and analyzed.

\subsection{Descriptive Statistics}

Table 1 presents descriptive statistics of the SLWAI.

Table 1. Descriptive Statistics of the SLWAI (General)

\begin{tabular}{ccccc}
\hline & Number & Minimum & Maximum & Mean \\
\hline High anxiety & 18 & 69 & 93 & 88.77 \\
Moderate anxiety & 13 & 53 & 61 & 59.38 \\
Low anxiety & 14 & 38 & 48 & 43.57 \\
Total & 45 & 38 & 93 & 66.90 \\
\hline
\end{tabular}

The above table shows a high level of ESL writing anxiety (Mean=66.90>65) among Iranian EFL students with different proficiency levels. The participants' scores in this study ranged from 38 to 93. In addition, 18 students were found to have high levels of anxiety, which might reinforce the conclusion that there is a high level of L2 writing anxiety among Iranian EFL students. Table 2 indicates descriptive statistics of SLWAI of the elementary level.

Table 2. Descriptive Statistics of the SLWAI (Elementary)

\begin{tabular}{ccccc}
\hline & Number & Minimum & Maximum & Mean \\
\hline High anxiety & 9 & 72 & 93 & 89.92 \\
Moderate anxiety & 4 & 54 & 61 & 59.67 \\
Low anxiety & 2 & 39 & 48 & 46.53 \\
Total & 15 & 39 & 93 & 65.37 \\
\hline
\end{tabular}

As revealed in above table, the students with elementary proficiency level in general have a high level of English writing anxiety $(M=65.37>65)$. Table 3 shows descriptive statistics of SLWAI of the intermediate level.

Table 3. Descriptive Statistics of the SLWAI (Intermediate)

\begin{tabular}{ccccc}
\hline & Number & Minimum & Maximum & Mean \\
\hline High anxiety & 6 & 71 & 89 & 84.39 \\
Moderate anxiety & 6 & 53 & 57 & 56.42 \\
Low anxiety & 3 & 40 & 43 & 41.76 \\
Total & 15 & 40 & 89 & 60.86 \\
\hline
\end{tabular}

This table indicates that the students with intermediate proficiency level in general have moderate level of English writing anxiety $(M=60.86<65)$. Table 4 reveals descriptive statistics of SLWAI of the advanced level.

Table 4. Descriptive Statistics of the SLWAI (Advanced)

\begin{tabular}{ccccc}
\hline & Number & Minimum & Maximum & Mean \\
\hline High anxiety & 3 & 69 & 86 & 80.22 \\
Moderate anxiety & 3 & 53 & 58 & 56.63 \\
Low anxiety & 9 & 38 & 40 & 38.86 \\
Total & 15 & 38 & 86 & 58.57 \\
\hline
\end{tabular}

As it can be seen, the students with advanced proficiency level in general have moderate level of English writing anxiety $(M=58.57<65)$. To find whether the above descriptive statistics are statistically significant or not, ANOVA was run to analyze the data (Table 5).

Table 5. One-way ANOVA of Difference between Anxiety Levels in Different Language Proficiency Levels

\begin{tabular}{cccccc}
\hline & Sum of Squares & df & mean Square & F & Sig. \\
\hline Between Groups & 704.844 & 2 & 352.422 & 3.988 & .026 \\
Within Groups & 3711.467 & 42 & 88.368 & & \\
& & & & & \\
Total & 4416.311 & 44 & & & \\
\hline
\end{tabular}

\footnotetext{
*. The means difference is significant at the 0.05 level.
} 
This table indicates that there exists a statistically significant difference between the mean scores of samples having different language proficiency levels with regard to their responses to writing anxiety items. To represent the exact place of difference in anxiety level among various language proficiency levels, post hoc (HSD) test was adopted (Table $6)$.

Table 6. Results of Tukey (HSD) among Language Proficiency Levels

\begin{tabular}{|c|c|c|c|c|c|c|}
\hline \multirow{3}{*}{ advanced } & & $\begin{array}{c}\text { mean } \\
\text { Difference }\end{array}$ & Std. Error & Sig. & Lower Bound & $\begin{array}{l}\text { Upper } \\
\text { Bound }\end{array}$ \\
\hline & intermediate & 4.20000 & 3.43256 & .446 & -12.5394 & 4.1394 \\
\hline & Elementary & 9.66667 & 3.43256 & .020 & -18.0060 & -1.3273 \\
\hline intermediate & Elementary & 5.46667 & 3.43256 & .260 & -13.8060 & 2.8727 \\
\hline
\end{tabular}

*. The means difference is significant at the 0.05 level.

The results shows that there is not any meaningful difference between advance and intermediate level in writing anxiety, but there is meaningful difference between advance and elementary level $(\mathrm{F}=3.43, \mathrm{p}=0.020)$. Furthermore, Table 6 states that there is not any significant difference between intermediate and elementary level in writing anxiety. Table 7 shows descriptive statistics of the three types of SLWAI among different proficiency levels.

Table 7. Descriptive Analysis of the Three Types of ESL Writing Anxiety among Different Language Proficiency levels

\begin{tabular}{ccccc}
\hline & & Cognitive & Somatic & Avoidance Behavior \\
\hline Elementary & $\mathrm{N}$ & 15 & 15 & 15 \\
& $\mathrm{Mean}$ & 23.8667 & 19.2000 & 23.0000 \\
& Std.Deviation & 4.47001 & 2.65115 & 5.56776 \\
Intermediate & $\mathrm{N}$ & 15 & 15 & 15 \\
& $\mathrm{Mean}$ & 21.0667 & 17.5333 & 18.7333 \\
& Std.Deviation & 5.10555 & 2.50333 & 3.57505 \\
Advanced & $\mathrm{N}$ & 15 & 15 & 15 \\
& $\mathrm{Mean}$ & 19.1333 & 19.6000 & 19.7333 \\
& Std.Deviation & 3.15926 & 3.73784 & 4.69752 \\
& & & & \\
\hline
\end{tabular}

As it can be seen, the mean score of cognitive anxiety in students with the elementary level $(M=23.86 ; S D=4.47)$ is greater than that of the somatic anxiety and avoidance behavior so that cognitive anxiety is the most common type of writing anxiety among Iranian EFL students.

\section{Discussion \& Conclusion}

Regarding the significant role of anxiety as the main problem in language learning, the main reason behind doing this study was to see whether or not the students in different language proficiency levels differ in the level of anxiety. Variables such as anxiety and different language proficiency levels were taken into consideration through ANOVA. As the results of this study indicated, there exists a high level of ESL writing anxiety among Iranian EFL students. A significant difference in anxiety was found among students with different proficiency levels (elementary, intermediate, and advanced) that is, students with elementary level in this study were found to suffer a higher level of English writing anxiety than the students with intermediate and advanced levels. The results of the present study confirm the findings of other researchers which found students with low proficiency tend to be more apprehensive due to lack of exposures to vocabulary and language skills (Nor Shidrah et al; 2006). Similarly, Young (1991) claims that comparing low and high proficiency learners, anxiety affects foreign language learners with low levels of oral proficiency more than those with high level of proficiency. However, the results of the present study, contrasts with Onwuegbuize et al (1999) study, which examined anxiety at three different levels (beginning, intermediate, and advanced). They reported that students experienced an almost linear rise in anxiety as years of study advanced. The obtained findings revealed that, high anxiety can lead to students' discouragement, loss of ability, and escaping from participation in classroom activities. The findings also revealed that cognitive anxiety was recognized as the main type of writing anxiety among Iranian EFL students. Cognitive anxiety deals with fear of teachers' negative feedback, low self-confidence in writing and poor linguistic knowledge. Such conclusion provides several implications for the results. It should be noted that teachers must be careful about the threats of anxiety and try to make the atmosphere of class as stress-free as possible in order to help students' performance in different language skills. Of course, there must also be consideration of students' levels as well. An understanding of learners' second language anxiety can inform the teachers to the possible causes of their students' low achievement in English, encouraging them to increase their efforts in bringing down the affective filters of the learners, with which anxiety plays a significant role (Krashen, 1985). As a result, the learners might be able to receive greater 'language input' which in turn can result in a better learner output. Teachers must also be providing affective feedback in order to increase their self-confidence in language learning. After all, it ought to be asserted that since the current survey was done with a fairly low number of learners, the obtained results can't be utterly generalized to other contexts, and hence other similar studies are called for to investigate different other noteworthy aspects of the issue at hand. It would be a good idea that other studies to be conducted tries to recognize the differences between 
different genders or different age ranges and also educational background in their studies. Although in this study the most widely scale for measuring anxiety was used, it is also possible to observe subjects' anxiety in other ways like, observation, interviewing learners, etc.

\section{References}

Aida, Y. (1994). Examination of Horwitz, Horwitz, and Cope's construct of foreign language anxiety: the case of students of Japanese. Modern Language Journal, 78,155-168.

Alpert, R, \& Haber, R.N. (1960). Anxiety in academic achievement situations. Journal of Abnormal and Social Psychology, 61(2), 207-215.

Brown, H.D. (2000). Principles language learning and teaching. New York: Addision Wesley Longman.

Cheng, Y. (2002). Factors associated with foreign language writing anxiety. Foreign Language Annals, 35, 647-656.

Chen, M. C. \& Lin, H. J. (2009). Self-efficacy, foreign language anxiety as predictors of academic performance among professional program students in general English proficiency writing test. Perceptual and Motor Skills, 109(2), 420-430. doi:10.2466/PMS.109.2.420-430.

Cheng, Y.S. (2004). A measure of second language writing anxiety: Scale development and preliminary validation. Journal of Second Language Writing, 13(4), 313-335. doi:10.1016/j.jslw.2004.07.001.

Daly, J. A. \& Wilson, D. A. (1983). Writing apprehension, self-esteem, and personality. Research in the Teaching of English, 17(4), 327-341. Retrieved from http://www.jstor.org/stable/i40004695.

Ehrman, M.E. (1996). Understanding second language learning difficulties London: Sage Publication, Inc.

Hassan, B. A. (2001). The relationship of writing apprehension and self-esteem to the writing quantity and quality of EFL University students. Mansoura Faculty of Education Journal, [online] Available at: http: //eric. Ed. Gov/ PDFS/ ED 459671. Pdf [Accessed: March. 20, 2011]

Horwitz, E. K. (1986). Preliminary evidence for the reliability and validity of a foreign language anxiety scale. TESOL Quarterly, 20(3), 559-562.

Horwitz, E. K. (2001). Language anxiety and achievement. Annual Review of Applied Linguistics, 21,112-126.

Horwitz, E.K., Horwitz, M.B\& Cope, J. (1986). Foreign language classroom anxiety. The Modern Language Journal, 70,125-132.

Krashen, S. (1985). The Input Hypothesis. London: Longman

MacIntyre, P.D, \& Gardner, R.C.(1991). Methods and results in the study of anxiety and language learning: A review of the litreture. Language Learning, vol, 41, no, 1, P.85-117.

Nor Shidrahet al, (2006). Second language writing anxiety: Cause or effect? Retrieved September 15, 2010.

Onwuegbuzie, Anthony., Bailey, P., Christine, E. and Daley. (1999). Factors Associated With Foreign Language Anxiety. Applied Socio Linguistics, 20 (2), 218-239.

Rollinson, P.(2005). Using peer feedback in the ESL writing class. ELT Journal, 59(1), 23-30.

Saito, Y. \& Samimy, K. (1996). Foreign language anxiety and language performance: A study of learning anxiety in beginning, intermediate, and advanced-level college students of Japanese Foreign Language Annals, 29(2), 239-390.

Scovel, T. (1978). The effect of affect on foreign language learning: A review of the anxiety research. Language learning, 28(1), 129-141.

Spielberger, C. (1983). Manual of state -trait anxiety inventory (STAI- Form Y). Palo Alto, CA: Consulting Psychologists Press.

Spielmann, G., \& Radnofsky, M. L. (2001). Learning language under tension: New directions from a qualitative study. The Modern Language Journal, 85(2), 259-278. doi:10.1111/j.1944-9720.1996.tb02330.

Tyrer, P. (1999). Anxiety: A Multidisciplinary review. London, United Kingdom: Imperial College Press.

Young, D. J. (1991). Creating a low-anxiety classroom environment: What does the language anxiety research suggest? Modern Language Journal, 75, 426-437. 